\title{
Individualization of the learning process consistent with the theory of multiple intelligences and learners' cultural-cognitive profiles
}

\author{
Margarita Finko* \\ Don State Technical University, Congress Hall Director, 1 Gagarin Square, Rostov-on-Don, Russia
}

\begin{abstract}
The present paper considers the practices that could be applied to individualize the learning process in view of students' intellectual and cultural-cognitive profiles. The article aims to investigate some of the theories and approaches pertaining to the realm of didactics and recognizing learners' personal and psychophysiological needs. This line of research shall be productive in analyzing possible opportunities for differentiation and individualization of learning, which are one of the key prerequisites for the promotion of learning efficiency.
\end{abstract}

\section{Introduction}

Russian system of education is founded on the systemic-functional approach relying on the recognition of age, psychological and physiological peculiarities of students in the learning process. This approach is designed to amplify students' individual capacities and allows for considerable consolidation of knowledge, as well as measurable speed-up of content mastery. These processes also imply the need for a self-adjusting multilevel learning environment, which is essentially about giving every student an opportunity to choose their individual learning trajectory, while providing for the guaranteed coverage of the compulsory minimum.

One of the didactic principles underlying this approach is the minimax rule, which implies that an educational institution offers ad maximum educational services and makes provisions for their assimilation at the level of the socially permissible minimum. The minimax rule realized in the framework of the personalized approach helps ensure quality education complying with the learners' individual intellectual, cultural and cognitive capacities.

The present paper considers the practices that could be applied to individualize the learning process in view of students' intellectual and cultural-cognitive profiles. The article aims to investigate some of the theories and approaches pertaining to the realm of didactics and recognizing learners' personal and psychophysiological needs. This line of research shall be productive in analyzing possible opportunities for differentiation and individualization of learning, which are one of the key prerequisites for the promotion of learning efficiency.

\footnotetext{
* Corresponding author: mfinko@mail.ru
} 


\section{Global intelligence}

In terms of practical and experimental coverage, the most broadly examined human intellectual functions are the ones associated with our rational behavior in solving logical tasks involving mass data processing. However, research advancements in this respect appear rather modest: although scholars have by now managed to collect ample empirical data retrieved within various areas of humanitarian research, there is still a considerable array of unresolved matters having to do with the way intelligence operates. Psychologists and sociologists define intelligence as "the capacity to address issues in a non-programmed (creative) way" [1], "aptitude to think rationally and interact reasonably and efficiently" [2], or "general innate cognitive abilities" [3].

In this day and age, some psychologists still view intelligence as a more or less hereditary factor. Yet, a considerable number of contemporary neuroresearchers believe that our intellectual development is only constrained by our commitment to pursue this objective.

Modern intelligence models are generally constructionist in nature and are associated with maintaining the all-embracing function of world cognition. Thus, for example, Deary et al. believe that intelligence presents a system of psychic mechanisms fabricating the objective representation of reality "within" an individual. Its key purpose lies in the establishment of specific representations attributable to the reproduction of objective awareness. Objectivity is associated with our competency to exercise adequate behavioral patterns in the world we construct. Therefore, a person of low intelligence constructs an "non-objective world image" [4] (although there are actually no criteria one could apply to measure objectivity).

There are two essentially different approaches in defining intelligence - the general and the distributed ones. Pursuant to the first approach, intelligence is interpreted as an integral brain feature signaling its capacity to address emergent problems [5]. This type of intelligence is predicated upon intelligence quotient - IQ. It is believed that the IQ test identifies intelligence quotient pegged to a person's genetic factors. In the framework of the various kinds of IQ tests, the quotient may be defined by 70 to 120 types of intelligence indicators. Yet practical experience attests that academic education, as well as analytical and logical faculties (i.e. all the aspects we normally associate with IQ) have nothing to do with an individual's capacity to succeed in life. A well-accomplished high school and university graduate will all too often end up a non-achiever, and a metamorphosis like this not at all uncommon. At the same time, building on such faculties as dexterousness, intuitive insight, stress resistance, networking and decision-making skills one may in the long run turn into an accomplished businessman and a powerful leader. These are the qualities that psychologists refer to as EQ - the emotional intelligence [6].

As noted by a well-known French psychologist Serge Ginger, every day people converge their genetic inheritance with the real life by integrating their experience in their behavioral patterns [7]. Apprehending our goals within this process, what we do is actually create our future. Apprehension of goals and inclinations, adequate perception of reality supported by appropriate responses to the surroundings, synthesis and systemic reasoning are the key dimensions of intelligence unrelated to logic, analysis or linear thinking accounted for by the left brain, while these functions of emotional intelligence are supported by the right brain.

According to Reuven Feuerstein, an Israeli clinical, developmental, and cognitive psychologist, boosting one's mental functioning (i.e. getting smarter) is a task one might accomplish at any age at any level of maturity [8]. Therefore, natural selection of intellectual capacities is a self-governed process supervised solely by an individual, and this point of view is what laid the groundwork for the emergence of the second approach to defining intelligence. 


\section{Multiple intelligences}

Pursuant to the second approach, specific problems are addressed through the inventory of measurably independent computational processes. This approach can be most vividly exemplified by the theory of multiple intelligences proposed by Howard Gardner in 1983 and referring to intelligence as a phenomenon explicated in various specific (primarily, sensory) contexts, rather than as dominance of a single general propensity towards something. Gardner singles out three meanings of the word "intelligence": a characteristic trait of all human beings (each one of us has seven types of intelligences in our possession); a feature distinguishing people from one another (no two human beings will ever be registered having identical intellectual profiles); and a means of addressing specific tasks in view of one's personal interests [9].

In the framework of the proposed theory, Gardner allocates seven types of intellectual abilities and the corresponding types of activity: verbal-linguistic - ability to master both oral and written language forms, including the propensity for foreign language mastery ("poet"); logical-mathematical - ability to analyze issues, exercise logical reasoning, handle mathematical computations, conduct research ("scientist"); visual-spatial - ability to accurately perceive, transform and modify visual objects ("architect"); musical-rhythmical ability to not only compose and perform music conforming to various scale, rhythm and timbre specifications, but to generally apprehend music as well ("composer"); somatickinesthetic - absolute body control and ingenious object manipulation ("dancer"); interpersonal - skillful discrimination of other people's feelings and mood, as well as the ability to use this information to exercise control over people's behavior ("leader"); intrapersonal - skillful discrimination of one's own feelings and mood, propensity for selfactualization, self-evaluation, self-identification ("engaging in self-reflection") [10].

The latter two types of intelligence (interpersonal and intrapersonal) amount to the aforementioned emotional intelligence (EQ), which represents a person's "commonsensical attributes" (emotional equivalent of the gnostic IQ). This is what defines our propensity for leadership, success, happiness and confidence in the world of human relations. As opposed to IQ, which barely ever changes throughout a person's life, the quotient of our emotional intelligence never remains the same teenage years onwards. Anybody can learn and develop their intellectual capacities through training and regular practice.

Studies have revealed that the most successful companies were those employing people with high EQ. Strange as it may seem, the post-industrial society sets great store by emotions - a driving force behind a person's professional and personal prosperity. They are the key criteria defining consumers' choice of branded articles, and an indispensable attribute of negotiation, for an ounce of emotion brought in at a critical moment may prove more efficient than a ton of figures and facts [11].

Thus, in analyzing personal educational goals, the theory of multiple intelligences might prove helpful, especially if the goal involves mastery of a range of disciplines. In this case, one might activate all seven intelligences in order to handle the ambitious task. At that, a teacher's key task lies in determining which of the tools need to be mobilized to help the student assimilate knowledge and skills consistent with their personal goals and inclinations.

\section{Cultural-cognitive profile}

Most of the conceptual paradigms interpreting intelligence suggest its substantive association with individual cultural and cognitive experience, and when it comes to individualization of the learning process it is this cultural and cognitive conditioning of intellectual abilities that defines the importance of the so-called learners' cultural-cognitive profiles. 
We believe that in order to identify the parameters of learners' cultural-cognitive profile, one will have to draw on the specific processes involved in the course of educational activity and view student profiles as a two-dimensional formation incorporating their temperament types (cognitive perspective) and cultural background (cultural perspective).

The cognitive perspective shall be defined by a set of individual psychophysiological features associated with dynamic, rather than substantive aspects of activity. Such set of specified features of an individual is generally referred to as temperament [12]. Temperament presents the cornerstone of character development. From the physiological perspective, it is manifested in a person's behavior (character), his or her vitality, which aspects will inevitably impact the learning process. Some of the peculiarities of temperament types relevant to the educational activity are listed in Table 1 below.

Table 1. Temperament types and their preferred treatment in the classroom.

\begin{tabular}{|c|c|c|}
\hline Temperament type & Student profile & Preferred treatment \\
\hline Sanguine & $\begin{array}{l}\text { Absorbs information quickly and easily. } \\
\text { Grasps the material promptly if it is } \\
\text { presented graphically. Inquisitive and } \\
\text { enterprising. Gets bored rapidly. Gets } \\
\text { enthusiastic quickly, yet loses interest } \\
\text { just as quick. }\end{array}$ & $\begin{array}{l}\text { Needs tasks that meet his/her own } \\
\text { interests. Frequent challenging is } \\
\text { preferred. }\end{array}$ \\
\hline Melancholic & $\begin{array}{l}\text { Absorbs information slowly, yet deeply. } \\
\text { Often finds it difficult to interact with the } \\
\text { group due to inability to stand up for } \\
\text { himself/herself. Does better in written } \\
\text { tests, especially home tasks. Commonly } \\
\text { performs poorly in group sessions. }\end{array}$ & $\begin{array}{l}\text { Needs emotional support and positive } \\
\text { evaluation. Requires reinforcement of } \\
\text { communicative skills through public } \\
\text { activity and progressive introduction to } \\
\text { the group. }\end{array}$ \\
\hline Choleric & $\begin{array}{l}\text { Characterized by intensive and vivid } \\
\text { emotional response. Persistent, yet tends } \\
\text { to overestimate his/her abilities. Assumes } \\
\text { the role of a leader in group sessions and } \\
\text { stands out. Gets hyperactive, yet exhibits } \\
\text { prompt mental processing. }\end{array}$ & $\begin{array}{l}\text { Needs to learn to be composed and } \\
\text { reserved. Tasks associated with } \\
\text { displaying independence, responsibility } \\
\text { and creativity are advisable. Moderate } \\
\text { control is required. }\end{array}$ \\
\hline Phlegmatic & $\begin{array}{l}\text { Commonly slow and marginally } \\
\text { perceptive. Appears indolent, lazy, } \\
\text { indifferent and egoistic. Usually even- } \\
\text { tempered. Absorbs information slowly, } \\
\text { yet stores it for a long time and } \\
\text { permanently. Has a propensity to perform } \\
\text { repetitive activities, finds it difficult to } \\
\text { shift from one type activity to another. } \\
\text { Performs slowly in group sessions, yet is } \\
\text { successful in fulfilling identical tasks. }\end{array}$ & $\begin{array}{l}\text { Needs to be given time to memorize the } \\
\text { task. Monitoring of task completion is } \\
\text { required. It is advisable to catalyze } \\
\text { activity at a certain pace, exclude } \\
\text { frequent shifting from one type of } \\
\text { activity to another. Needs to be } \\
\text { interested in what he/she is doing. }\end{array}$ \\
\hline
\end{tabular}

Alongside careful consideration of learners' temperament types, individualization of the learning process will also require accurate registration of their cultural background (cultural perspective). A student's cultural profile comprises a number of parameters, which underlie the analysis of culturally determined aspects of behavior, reasoning and activity. These parameters can be roughly broken down into cognitive (incorporating the specifics of data processing, cognizance, decision making and creativity) and operational (specifying the way time, society, surroundings and context are being perceived). The parameters specifying a learner's cognitive profile can be presented in the form of a cross-cutting reference documenting the way the various aspects of cognitive and operational setting correlate with culture types (as defined in [13]) (Table 2).

Table 2. Parameters specifying a learner's cultural-cognitive profile.

\begin{tabular}{|l|l|l|l|}
\hline Specification & Type I & Type II & Type III \\
\hline \multicolumn{3}{|c|}{ COGNITIVE SETTING } \\
\hline
\end{tabular}




\begin{tabular}{|c|c|c|c|}
\hline $\begin{array}{l}\text { Data } \\
\text { processing }\end{array}$ & $\begin{array}{l}\text { Careful consideration of } \\
\text { contextual information } \\
\text { (high-context culture). }\end{array}$ & $\begin{array}{l}\text { Moderate consideration of } \\
\text { contextual information. }\end{array}$ & $\begin{array}{l}\text { Poor consideration of } \\
\text { contextual information (low- } \\
\text { context culture). }\end{array}$ \\
\hline Cognizance & Focus on the general scope. & $\begin{array}{l}\text { Focus on objects within the } \\
\text { general scope. }\end{array}$ & Focus on the general scope. \\
\hline $\begin{array}{l}\text { Decision } \\
\text { making }\end{array}$ & $\begin{array}{l}\text { Focus on expert opinion, } \\
\text { inclusion of others into the } \\
\text { decision-making process, } \\
\text { avoidance of uncertainty. }\end{array}$ & $\begin{array}{l}\text { Focus on the freedom of } \\
\text { choice within socially } \\
\text { accepted boundaries. }\end{array}$ & $\begin{array}{l}\text { Focus on personal opinion, } \\
\text { tolerant attitude towards } \\
\text { uncertainty. }\end{array}$ \\
\hline Creativity & $\begin{array}{l}\text { Interpretation in the } \\
\text { framework of existing } \\
\text { tradition. }\end{array}$ & $\begin{array}{l}\text { Creation of new things within } \\
\text { a broadened traditional } \\
\text { framework. }\end{array}$ & Focus on in \\
\hline \multicolumn{4}{|c|}{ OPERATIONAL SETTING } \\
\hline $\begin{array}{l}\text { Perception of } \\
\text { time }\end{array}$ & $\begin{array}{l}\text { Time as a non-linear entity } \\
\text { (cyclical). }\end{array}$ & $\begin{array}{l}\text { Time as a limited resource } \\
\text { coupled } \quad \text { with } \\
\text { undervaluation. }\end{array}$ & $\begin{array}{l}\text { Time as a linear high-valued } \\
\text { entity. }\end{array}$ \\
\hline $\begin{array}{l}\text { Perception of } \\
\text { society }\end{array}$ & $\begin{array}{l}\text { Collectivist cultures, high } \\
\text { power distance. }\end{array}$ & $\begin{array}{l}\text { Opportunities to approve } \\
\text { oneself within the } \\
\text { hierarchical } \\
\text { Medium power distance. }\end{array}$ & $\begin{array}{l}\text { Individualistic cultures. Low } \\
\text { power distance. }\end{array}$ \\
\hline $\begin{array}{l}\text { Perception of } \\
\text { surroundings }\end{array}$ & $\begin{array}{l}\text { In harmony with the } \\
\text { surroundings. }\end{array}$ & $\begin{array}{l}\text { The surroundings as a } \\
\text { moderately efficient source } \\
\text { of satisfaction. }\end{array}$ & $\begin{array}{l}\text { Control over the } \\
\text { surroundings. }\end{array}$ \\
\hline $\begin{array}{l}\text { Perception of } \\
\text { context }\end{array}$ & $\begin{array}{l}\text { High-context cultures. } \\
\text { Multidimensional } \\
\text { argumentation. Conclusion } \\
\text { is proof (deduction). }\end{array}$ & $\begin{array}{l}\text { Focus on information } \\
\text { structures within the context. } \\
\text { Superficial links between the } \\
\text { structures. }\end{array}$ & $\begin{array}{l}\text { Low-context cultures. Linear } \\
\text { argumentation relying on } \\
\text { facts (induction). }\end{array}$ \\
\hline
\end{tabular}

Thus, combining the two aspects of learners' profiles - temperament types and cultural background - an educator can adapt the learning content to a student's individual and culturally determined specific features.

\section{Discussion and results for practical application}

Drawing on the proposed analysis of the theory of multiple intelligences and the suggested parameters of students' cultural-cognitive profiles, we can suggest the following recommendations for the individualization of the learning process (Table 3).

Table 3. Recommendations for the individualization of the learning process.

\begin{tabular}{|l|l|l|}
\hline Intelligence type & Operational reference & Appropriate activity \\
\hline Verbal-linguistic & $\begin{array}{l}\text { The student can read } \\
\text { about this principle }\end{array}$ & $\begin{array}{l}\text { The student can read, make notes, share ideas through an } \\
\text { online blog; compile texts using text editors, highlighting the } \\
\text { key aspects by applying bullet lists, styles, font sizes and } \\
\text { colors; make use of search engines to browse and compare } \\
\text { articles, opinions, headlines and sources. }\end{array}$ \\
\hline $\begin{array}{l}\text { Logical- } \\
\text { mathematical }\end{array}$ & $\begin{array}{l}\text { The student can study the } \\
\text { mathematical formulas } \\
\text { expressing this principle }\end{array}$ & $\begin{array}{l}\text { The student can create formulas in text editing apps using } \\
\text { math plugins in order to represent equations in the form of } \\
\text { two- or three-dimensional graphs; share information through } \\
\text { blogs to discuss it and get feedback. }\end{array}$ \\
\hline Visual-spatial & $\begin{array}{l}\text { The student can study a } \\
\text { graph / diagram } \\
\text { illustrating this principle }\end{array}$ & $\begin{array}{l}\text { The student can create various schemes and graphs; share } \\
\text { information through blogs to discuss it and get feedback; } \\
\text { create video clips, movies, graphic narratives, or compile } \\
\text { presentations for content visualization. }\end{array}$ \\
\hline Interpersonal & $\begin{array}{l}\text { The student can observe } \\
\text { the way this law } \\
\text { functions within his/her } \\
\text { professional sphere }\end{array}$ & $\begin{array}{l}\text { The student can interview experts and register their feedback } \\
\text { in digital form (pictures, video or audio content); hold remote } \\
\text { interviews using e-mail apps or videoconferencing apps; } \\
\text { create video clips, movies, graphic narratives, or compile } \\
\text { presentations for content visualization. }\end{array}$ \\
\hline $\begin{array}{l}\text { Somatic- } \\
\text { kinesthetic }\end{array}$ & $\begin{array}{l}\text { The student can study the } \\
\text { way this law functions }\end{array}$ & $\begin{array}{l}\text { The student can register his/her observations in digital format } \\
\text { to have an opportunity to study them again later; create video }\end{array}$ \\
\hline
\end{tabular}




\begin{tabular}{|l|l|l|}
\hline & $\begin{array}{l}\text { drawing on the example } \\
\text { of his/her own body }\end{array}$ & $\begin{array}{l}\text { clips, movies, graphic narratives; compile presentations to } \\
\text { illustrate his/her experience and associate personal somatic } \\
\text { perceptions with the observations registered. }\end{array}$ \\
\hline $\begin{array}{l}\text { Musical- } \\
\text { rhythmical }\end{array}$ & $\begin{array}{l}\text { The student can write } \\
\text { his/her own song or find } \\
\text { an already existing one }\end{array}$ & $\begin{array}{l}\text { The student can record original songs or add soundtracks; } \\
\text { share songs through his/her personal blog or upload them } \\
\text { online to get prompt feedback; find existing songs online } \\
\text { using search engines. }\end{array}$ \\
\hline Intrapersonal & $\begin{array}{l}\text { The student can study the } \\
\text { way this law functions by } \\
\text { personal example }\end{array}$ & $\begin{array}{l}\text { The student can record introspection in digital format to have } \\
\text { an opportunity look into the recorded observations later; } \\
\text { create video clips, movies, graphic narratives; compile } \\
\text { presentations to illustrate his/her experience and associate } \\
\text { personal perceptions with the observations registered. }\end{array}$ \\
\hline
\end{tabular}

\section{Conclusion}

Efficiency and productivity of learning is a priority objective for all participants of the educational process. The learning process needs to be adjusted in view of students' psychophysiological features, for this is one of the key prerequisites for the implementation of the systemic-functional approach to education. Such adjustment will require individualization of the learning process by virtue of extended and versatile modes of content presentation. This is where multiple intelligences and cultural-cognitive profiles can help educators choose appropriate ways of interaction. Building on these theories, teachers will be able to provide adequate material and devise auxiliary aids to develop students' intellectual potential and, possibly, balance out their intellectual limitations. This, in turn, shall change the very role and objectives of the educator, whose main task is no longer associated with teaching, but rather involves encouragement, evaluation and analysis. The teacher is no longer a source of information, but an administrator of the knowledge transfer process, a source of spiritual and intellectual impulse galvanizing learners into action.

\section{References}

1. S.J. Gould, Ever since Darwin: reflections in natural history (WW Norton \& Company, New York, 1992)

2. D. Wechsler, Wechsler adult intelligence scale (NCS Pearson, San Antonio, 2008)

3. C. Burt, Am. Psychol. 13, 1, 1 (1958)

4. I.J. Deary, S. Strand, P. Smith, C. Fernandes, Intelligence, 35, 1, 19 (2007)

5. R.C. Meldrum, M.A. Petkovsek, B.B. Boutwell, J.T. Young, Intelligence, 60 (2017)

6. L. Kevereski, M. Kotevska Dimovska, D. Ristevski, IJCRSEE, 4, 1 (2016)

7. S. Ginger, La Gestalt: une therapie du contact (Hommes et Groupes, Paris, 2000)

8. R. Feuerstein, S. Feuerstein, L. Falik, Y. Rand, Dynamic assessments of cognitive modifiability (ICELP Press, Jerusalem, 2002)

9. H. Gardner, Frames of mind: the theory of multiple intelligences (Basics, New York, 1983)

10. H. Gardner, T. Hatch, Educ. Res. 18, 8 (1989)

11. D.P. Goleman, Emotional intelligence: why it can matter more than IQ for character, health and lifelong achievement (Bantam Books, New York, 1995)

12. H.L. Joshi, IJHW, 7, 1, 12 (2016)

13. G. Hofstede, Cultures and organizations: software of the mind (McGraw-Hill, Maidenhead, 1991) 